\title{
Interferon- $\gamma$ mediates the protective effects of soluble receptor for advanced glycation end-product in myocardial ischemia/reperfusion
}

\author{
Mengqiu Dang ${ }^{1} \cdot$ Xiangjun Zeng $^{2} \cdot$ Buxing Chen ${ }^{1} \cdot$ Hongxia Wang ${ }^{2} \cdot$ Huihua $\mathrm{Li}^{3,4} \cdot$ Fenghe $\mathrm{Du}^{1,5} \cdot$ Caixia Guo $\mathbb{D}^{1}$
}

Received: 14 January 2018 / Revised: 29 May 2018 / Accepted: 1 June 2018 / Published online: 8 August 2018

(c) United States \& Canadian Academy of Pathology 2018

\begin{abstract}
The ubiquitin-proteasome system (UPS) is essential for protein degradation and plays critical roles in myocardial ischemia/ reperfusion (MI/R) injuries. Previous studies have demonstrated that the soluble receptor for advanced glycation end-product (sRAGE) inhibited MI/R-induced apoptosis by upregulating proteasome subunits. However, the mechanism remains unknown. An MI/R model was established by left anterior descending (LAD) coronary artery ligation in mice. Recombinant sRAGE protein or saline was injected intramyocardially with or without neutralizing interferon- $\gamma$ (IFN- $\gamma$ ) antibody injected intraperitoneally before ligation. In cardiomyocytes, ischemia was simulated with "ischemia buffer" and sRAGE was overexpressed by adenovirus. Adenovirus expressing the interference RNA of $\beta 5 \mathrm{i}$ was used to knockdown $\beta 5 \mathrm{i}$ in cardiomyocytes. IFN- $\gamma$ was induced by sRAGE both in sham and MI/R mice. Blockade of IFN- $\gamma$ using IFN- $\gamma$ antibody abolished the rescue effects of sRAGE for cardiac dysfunction, infarct size and apoptosis provoked by MI/R. Blockade of IFN- $\gamma$ reversed the upregulation of $\beta 1 \mathrm{i}$ and $\beta 5 \mathrm{i}$ expression induced by sRAGE during MI/R in heart, accompanied by decreasing chymotrypsin-like proteasome activity. In addition, IFN- $\gamma$ antibody abolished the suppressing effect of sRAGE on MI/R-induced p38 and c-Jun N-terminal kinase (JNK) activation, as well as p53 expression, both in vivo and in vitro. However, knockdown of $\beta 5 \mathrm{i}$ abolished the antiapoptosis effect of sRAGE during hypoxia/reoxygenation (H/R) in vitro, accompanied by decreased degradation of p53. Our data suggest a novel mechanism for sRAGE in preventing MI/R-induced apoptosis in heart: sRAGE inhibits MI/R-induced apoptosis in cardiomyocytes by degrading p53 by $\beta 5 \mathrm{i}$ subunit that is increased via upregulation of IFN- $\gamma$.
\end{abstract}

\section{Introduction}

The soluble receptor for advanced glycation end-product (sRAGE) is the soluble form of the receptor for advanced

These authors contributed equally: Mengqiu Dang, Xiangjun Zeng

Electronic supplementary material The online version of this article (https://doi.org/10.1038/s41374-018-0102-z) contains supplementary material, which is available to authorized users.

Fenghe Du

fhduu@sina.com

$\triangle$ Caixia Guo

cxgbb@163.com

1 Department of Cardiology, Beijing Tian Tan Hospital, Capital Medical University, 6 Tiantan Xili, Dongcheng District, 100050 Beijing, China

2 Department of Physiology and Pathophysiology, Capital Medical University, 100069 Beijing, China glycation end-product (RAGE), a cell surface molecule that is expressed on a wide variety of tissues such as heart, lung and blood vessels $[1,2]$. The extracellular region of RAGE could be separated from the cell membrane by disintegrin metalloprotease 10 or encoded by a mRNA modified from RAGE mRNA [3]. sRAGE acts as a competing factor to inhibit signaling pathways of RAGE that might induce tissue damage [4]. Several lines of evidence demonstrated that sRAGE, used as a pharmacological blocking agent against RAGE, reduced myocardial ischemia/reperfusion (MI/R)

3 Department of Cardiology, Institute of Cardiovascular Disease, First Affiliated Hospital of Dalian Medical University, 116011 Dalian, China

4 Department of Nutrition and Food Hygiene, School of Public Health, Advanced Institute of Medical Sciences, Dalian Medical University, 116044 Dalian, China

5 Department of Geriatrics, Beijing Tian Tan Hospital, Capital Medical University, 6 Tiantan Xili, Dongcheng District, 100050 Beijing, China 
injuries in mice [5-7]. Our previous studies showed that administration of recombinant sRAGE protein ameliorated MI/R-induced apoptosis in mice that was mediated by activation of Janus kinase2/signal transductor and activator transcription3 pathway [8], inhibition of the mitochondriamediated apoptosis pathway [9] and upregulation of the ubiquitin-proteasome system (UPS) [10]. However, the mechanism by which sRAGE upregulates proteasome expression and contributes to the inhibition of cardiac injuries during $\mathrm{MI} / \mathrm{R}$ remains to be elucidated.

UPS is a critical system in regulating protein homeostasis involving degradation of proteins by the 26 s proteasome after conjugation with ubiquitins [11]. The 26s proteasome is composed of a 19 s regulatory subunit and a 20 s catalytic subunit. The 20s subunit includes three constitutive catalytic subunits: $\beta 1, \beta 2$ and $\beta 5$ in the inner $\beta$-rings that can be replaced by inducible $\beta$-subunits, including $\beta 1 \mathrm{i}$ (LMP2 or PSMB9), $\beta 2 \mathrm{i}$ (MECL-1 or PSMB10) and $\beta 5 \mathrm{i}$ (LMP7 or PSMB8) [12]. It was demonstrated that UPS was involved in many cardiovascular diseases, including cardiac hypertrophy [13], angiotensin II-induced abdominal aortic aneurysm [14] and MI/R injuries [15]. Our previous studies showed that sRAGE protected the heart against $\mathrm{MI} / \mathrm{R}$ injuries by increasing the expression of $\beta 1 \mathrm{i}$ and $\beta 5 \mathrm{i}$ subunits [10], although the mechanism is still not understood.

It was reported that interferon- $\gamma($ IFN- $\gamma$ ) was a crucial factor that induced the expression of the immunoproteasome by increasing the levels of mRNA encoding $\beta$-subunits [16]. Studies on endogenous activity and properties of sRAGE showed that sRAGE dose dependently induced the production of cytokines, including interleukin6 , tumor necrosis factor- $\alpha$ and IFN- $\gamma$ in spleen cells that interact with $\beta 2$-integrin on macrophages to activate nuclear factor kappa B [17-19]. Due to the induction of inflammatory cytokines by sRAGE, it was postulated that the increase in the expression of proteasome subunits mediated by sRAGE during MI/R might be related to IFN- $\gamma$. To prove this hypothesis, the expression of IFN- $\gamma$ was measured with or without the existence of sRAGE during MI/R, and anti-IFN- $\gamma$ antibody was used to observe the effects of sRAGE on MI/R injuries and the expression of proteasome subunits after IFN- $\gamma$ was neutralized. Meanwhile, the effects of proteasome subunits on MI/R injuries in cardiomyocytes were evaluated as well.

\section{Materials and methods}

\section{Animals and treatment}

Eight- to 10-week-old adult male C57BL/6 mice were purchased from Vital River Laboratory Animal Technology Co. Ltd. (Beijing, China). The mice were randomly divided into five groups: the sham + saline group that was intramyocardially injected with saline without left anterior descending (LAD) ligation $(n=7)$; the sham + sRAGE group that was intramyocardially injected with recombinant sRAGE protein $(2 \mu \mathrm{g} /$ mouse, Aidi Bo biological Ltd. Beijing, China) without LAD ligation $(n=7)$; the MI/R + saline group that was intramyocardially injected with saline with LAD ligation $(n=8)$; the MI/R + sRAGE group that was intramyocardially injected with recombinant sRAGE protein $(2 \mu \mathrm{g} /$ mouse $)$ with LAD ligation $(n=8)$; and the $\mathrm{MI} / \mathrm{R}+\mathrm{sRAGE}+$ anti-IFN- $\gamma$ group that was intraperitoneally injected with anti-IFN- $\gamma$ antibody $(1 \mu \mathrm{g} / \mathrm{g}, \mathrm{R} \& \mathrm{D}$ System, Minneapolis, MN, USA) and intramyocardially injected with recombinant sRAGE protein $(2 \mu \mathrm{g} /$ mouse $)$ with LAD ligation $(n=8)$. The model of MI/R is described below. Recombinant sRAGE protein or saline was injected into mice heart just before LAD ligation. Saline or recombinant sRAGE protein in a total of $20 \mu \mathrm{l}$ was injected into five regions of the muscle in the peri-infarct zone using a syringe attached to a 30-gauge needle. The anti-IFN- $\gamma$ antibodies were injected intraperitoneally $30 \mathrm{~min}$ before LAD ligation. The mice were offered standard laboratory raising conditions in Capital Medical University Laboratory of Animal Experiments. All investigations were approved by the Institutional Animal Care and Use Committee of Capital Medical University and conformed to the Guide for the Care and Use of Laboratory Animals published by the US National Institutes of Health.

\section{$M I / R$ in mice}

The model of MI/R in mice was established by ligating the LAD as described previously [20]. Briefly, the mice were anesthetized with $2 \%$ isoflurane, and then the heart was exposed from the left fourth intercostal space. The LAD was ligated with 7-0 silk at the initial site. The slipknot was released after $30 \mathrm{~min}$, and reperfusion persisted for $24 \mathrm{~h}$ or 14 days. Mice in the sham group underwent the same operation without ligation. After reperfusion, the mice were sacrificed under anesthesia with tribromoethanol (100 mg/kg, Sigma-Aldrich, St Louis, MO, USA). Hearts were quickly removed for further analysis.

\section{MI/R in neonatal cardiomyocytes}

Cardiomyocytes were isolated from hearts of 1-2-day-old Sprague-Dawley rats purchased from Vital River Laboratory Animal Technology Co. Ltd. The method was described previously $[21,22]$. The hypoxia/reoxygenation $(\mathrm{H} / \mathrm{R})$ model in cardiomyocytes was established with "ischemia buffer" ( $\mathrm{pH}$ 6.3) including (mmol/l): $118 \mathrm{NaCl}, 24$ $\mathrm{NaHCO}_{3}, 1.0 \mathrm{NaH}_{2} \mathrm{PO}_{4}, 2.5 \mathrm{CaCl}_{2}-2 \mathrm{H}_{2} \mathrm{O}, 1.2 \mathrm{MgCl}_{2}$, 20 sodium lactate, $16 \mathrm{KCl}$ and 10 deoxyglucose. 
Cardiomyocytes were incubated with "ischemia buffer" for $2 \mathrm{~h}$ and then transferred to normal medium for $24 \mathrm{~h}$.

\section{Adenovirus infection}

Adenovirus-expressing sRAGE (Ad-sRAGE) and control adenovirus-expressing GFP (Ad-GFP) were purchased from Hanbio Co. Ltd. (Shanghai, China). The adenovirusexpressing $\beta 5 \mathrm{i}$ shRNA (Ad-si $\beta 5 \mathrm{i}$ ) and $\beta 1 \mathrm{i}$ shRNA (Adsi $\beta 11$ ) were purchased from Genechem Co. Ltd. (Shanghai, China). The RNA interference shRNA sequences of $\beta 1 i$ and $\beta 5 \mathrm{i}$ were 5'-ACCATCATGGCTGTGGAAT-3' and 5'-GG AATGCAGGCTATACTAT-3', respectively. Adenovirus transinfection in cardiomyocytes was as previously described [10]. Briefly, cardiomyocytes were transfected with adenovirus for $6-8 \mathrm{~h}$ in serum-free medium, and then were transferred to normal medium with $5 \%$ fetal bovine serum and were incubated for at least $24 \mathrm{~h}$.

\section{ELISA assay}

The level of IFN- $\gamma$ in the serum of mice was measured using mouse IFN- $\gamma$ ELISA Kit (CSB-E04578m; CUSABIO, Wuhan, China). The experiments were performed as previously described according to the manufacturer's instructions [23]. Briefly, $100 \mu \mathrm{l}$ of serum for each sample was added to the plate and incubated for $2 \mathrm{~h}$ at $37^{\circ} \mathrm{C}$. Then, the plate was incubated with biotin-labeled antibody for $60 \mathrm{~min}$ at $37^{\circ} \mathrm{C}$. Next, avidin-conjugated horseradish peroxidase was added to each plate and incubated for $60 \mathrm{~min}$ at $37^{\circ} \mathrm{C}$. Finally, the plate was incubated at $37^{\circ} \mathrm{C}$ for $15 \mathrm{~min}$ with substrate solution. The reaction was stopped with stopping buffer and the color was measured with a microplate reader (Eppendorf, Hamburg, Germany) at $450 \mathrm{~nm}$ of each sample. A standard curve for quantification was created with purified IFN- $\gamma$ in a concentration range from 0 to $1000 \mathrm{ng} / \mathrm{mL}$. The levels of each sample were calculated using the standard curve.

\section{Evaluation of cardiac function}

After reperfusion for $24 \mathrm{~h}$, the cardiac function of the mice was measured by the Vevo 2100 imaging system (VisualSonics Inc., Toronto, Ontario, Canada). The mice were anesthetized by intra-peritoneal injection with tribromoethanol $(100 \mathrm{mg} / \mathrm{kg}$, Sigma-Aldrich, St Louis, MO, USA). M-mode echocardiography was used to evaluate cardiac function.

\section{Evaluation of cardiac infarction}

Evans blue and 2'3'5-triphenyltetrazolium chloride(TTC) double staining were used to determine the myocardial infarct size. The protocol was described in detail previously [24]. The LAD was retied and the heart was removed quickly. The heart was perfused with $1 \%\left(\mathrm{wV}^{-1}\right)$ TTC (Sigma-Aldrich, St Louis, MO) from the aortic arch and was incubated for $5 \mathrm{~min}$ at $37^{\circ} \mathrm{C}$. The heart was fixed with $4 \%\left(\mathrm{wv}^{-1}\right)$ paraformaldehyde overnight after injection with $1 \%\left(\mathrm{wv}^{-1}\right)$ Evans blue (Sigma-Aldrich, St Louis, MO, USA) from the aortic arch. The next day, the heart was sectioned transversely $(1 \mathrm{~mm})$ and was imaged with a digital camera. The blue region represented viable tissue, whereas the white region represented infarcted tissue. The area of white plus red was represented as area at risk (AAR). The area of each region was quantified by ImageJ software (NIH). The infarct size was expressed as the percentage of the white region in AAR.

\section{TUNEL staining}

Terminal deoxynucleotidyl transferase dUTP nick end labeling (TUNEL) assays were used to evaluate apoptosis of cardiomyocytes in hearts. TUNEL staining was performed with the In Situ Cell Death Detection Kit (Roche Applied Science, Mannheim, Germany) according to manufacturer's instructions. Briefly, hearts were embedded with paraffin and sectioned to slices of $5 \mu \mathrm{m}$. After incubation at $4{ }^{\circ} \mathrm{C}$ in $0.1 \%\left(\mathrm{vv}^{-1}\right)$ Triton $\mathrm{X}-100$ for $15 \mathrm{~min}$, the sections were incubated with $50 \mu \mathrm{l}$ TUNEL mixture including $5 \mu \mathrm{l}$ of TUNEL enzyme and $45 \mu \mathrm{l}$ of fluorescein isothiocyanateconjugated dUTP at $37{ }^{\circ} \mathrm{C}$ for $60 \mathrm{~min}$. Then, the sections were stained with $\alpha$-actinin (Sigma-Aldrich, St Louis, MO, USA) and 4',6-diamidino-2-phenylindole (DAPI). The $\alpha$-actinin-positive cells indicated the cardiomyocytes. An Olympus BX63 Fluorescence Microscope (Olympus America Inc., Center Valley, PA) was used to capture the photographs. The number of TUNEL-positive cells and the $\alpha$-actinin-positive cells was counted with Image $\mathrm{J}(\mathrm{NIH})$ software. The results were expressed as the percentage of TUNEL-positive cells in the $\alpha$-actinin-positive cells.

\section{Quantitative real-time PCR analysis}

Quantitative real-time polymerase chain reaction (real-time PCR) was performed as described previously [25]. Approximately $1-2 \mu \mathrm{g}$ of total mRNA was reversetranscribed to complementary DNA (cDNA) using GoScriptTM reverse transcription system (S1000 Thermal Cycler, California, USA). Real-time PCR of each sample was performed as described below with $2 \mu$ of cDNA sample, $1 \mu \mathrm{l}$ of forward primer, $1 \mu \mathrm{l}$ of reverse primer, $10 \mu \mathrm{l}$ of SYBR Premix Ex Taq (Takara, Dalian, China) and $6 \mu \mathrm{l}$ of DNA-free water. The 7500 Real-Time PCR system (Applied Biosystems) was used to perform the experiments. The mouse primers were as follows: IFN- $\gamma$ : 5'-GGTTG 
TCTCCTGCGACTTCA-3' (forward), 5'-GGTGGTCCAG GGTTTCTTACTC-3' (reverse), GAPDH: 5'-ATGCCT CGGGAATGGAAAGG-3' (forward), 5'-TCTAGCGGCA TGAAGCACTC-3' (reverse).

\section{Proteasome activity assays}

The proteasome activity assay was determined as previously described $[15,26]$. Briefly, heart tissues were lysed with HEPES buffer ( $\mathrm{pH} 7.5$ ) containing $50 \mathrm{mmol} / \mathrm{l}$ HEPES, $20 \mathrm{mmol} / \mathrm{l} \mathrm{KCl}, 5 \mathrm{mmol} / \mathrm{l} \mathrm{MgCl}_{2}$ and $1 \mathrm{mmol} / \mathrm{l} \mathrm{DL}-$ dithiothreitol. The proteins were quantified with a BCA Protein Assay Kit (Thermo Scientific, Rockford, IL, USA). The caspase-like, trypsin-like and chymotrypsin-like activities were measured with the synthetic fluorescent substrates Z-LLE-AMC (45 mM), Ac-RLR-AMC $(40 \mathrm{mM})$ and SucLLVY-AMC $(18 \mathrm{mM})$, respectively. Finally, proteasome activity was quantified using a PerkinElmer 2030 Multilabel Microplate Reader with $380 \mathrm{~nm}$ excitation wavelength and $480 \mathrm{~nm}$ emission wavelength.

\section{Ubiquitination of p53}

Cardiomyocytes were lysed with lysis buffer containing $20 \mathrm{mmol} / \mathrm{L}$ Tris-Hcl (pH 7.5), $0.1 \%$ NP-40, $5 \mathrm{mmol} / \mathrm{L}$ $\mathrm{MgCl}_{2}, 10 \mathrm{mmol} / \mathrm{L} \mathrm{NaF}, 10 \mathrm{mmol} / \mathrm{L}$ Na-pyrophosphate, $10 \mathrm{mmol} / \mathrm{L} \beta$-glycerophosphate, $20 \%$ glycerol, $1 \mathrm{mmol} / \mathrm{L}$ DL-dithiothreitol and $1 \mathrm{mmol} / \mathrm{L}$ phenylmethanesulfonyl fluoride (Sigma-Aldrich, St Louis, MO, USA). The supernatants were collected after the lysates were centrifuged at $12,500 \mathrm{rpm}$ for $15 \mathrm{~min}$ at $4{ }^{\circ} \mathrm{C}$. Dynabeads Protein G (Invitrogen, USA) was incubated with anti-p53 antibody (9282 s, Cell Signaling Technology, Danvers, MA, USA) for $1 \mathrm{~h}$ at room temperature and were then washed three times with washing buffer including $50 \mathrm{mmol} / \mathrm{L}$ Tris-Hcl (pH 7.5), $0.5 \% \mathrm{NP}-40$ and $150 \mathrm{mmol} / \mathrm{L} \mathrm{NaCl}$. Then, the beads were incubated with the supernatants obtained from cell lysates at $4{ }^{\circ} \mathrm{C}$ overnight. Precipitated p53 protein was eluted using sodium dodecyl sulfate-Polyacrylamide gel electrophoresis (SDS-PAGE) sample buffer and was measured using anti-ubiquitin antibody.

\section{Immunohistochemistry}

The embedded hearts were sectioned into $5 \mu \mathrm{m}$ slices. The sections were incubated with IFN- $\gamma$ (AF-585-NA; Novus, Littleton, USA) or CD68 antibodies (ab125212, Abcam, Cambridge, UK) overnight at $4{ }^{\circ} \mathrm{C}$ after antigen retrieval in citrate buffer and antigen blocking with $3 \%$ bovine serum albumin. Finally, IFN- $\gamma$ or CD68 in the heart were detected by the horseradish peroxidase-DAB detection method. An Olympus BX63 Microscope (Olympus America Inc., Center Valley, PA) was used to capture the photographs.

\section{Western blot}

Western blot was performed as described previously [10]. Briefly, heart tissues or cardiomyocytes were lysed in lysis buffer (Solarbio, Beijing, China) containing $1 \mathrm{mM}$ phenylmethanesulfonyl fluoride at $4{ }^{\circ} \mathrm{C}$. The concentration of the protein was measured using a BCA Protein Assay Kit (Thermo Scientific, Rockford, IL, USA). Equivalent masses of proteins in each group were separated by $6-15 \%$ SDSPAGE. The proteins were transferred to polyvinylidene difluoride filter membranes by electroblotting. The membranes were blocked with $5 \%$ skim milk for $60 \mathrm{~min}$ and were incubated with primary antibodies overnight at $4{ }^{\circ} \mathrm{C}$. The membranes were developed with a chemiluminescence detection kit (Millipore, Billerica, MA, USA) and were captured with Chemiluminescent and Fluorescent Imaging Systems (ChampChemi; SAGECREATION, Beijing, China) after incubation with horseradish peroxidaseconjugated IgG antibody for $60 \mathrm{~min}$ at room temperature. Densitometry was calculated by ImageJ software (NIH). GAPDH or $\beta$-actin was used to verify equal loading.

Antibodies are as follows: c-Jun N-terminal kinase 1/2 (JNK1/2; 9252s, Cell Signaling Technology, Danvers, MA, USA); phosphorylated JNK1/2 (9255s, Cell Signaling Technology); p53 (9282s, Cell Signaling Technology); p38 (8690s, Cell Signaling Technology); phosphorylated p38 (4511s, Cell Signaling Technology); caspase-3 (9662s, Cell Signaling Technology); $\beta$-actin (4970s, Cell Signaling Technology); GAPDH (5174s, Cell Signaling Technology); $\beta 1 \mathrm{i}$ (ab3328, Abcam, Cambridge, UK); $\beta 2 \mathrm{i}$ (ab77735, Abcam); $\quad \beta 5$ i (ab3329, Abcam); ubiquitin (662056, Millipore, Billerica, MA, USA); horseradish peroxidaseconjugated IgG antibody (sc-2313, Santa Cruz Biotechnology, CA, USA).

\section{Statistical analysis}

All data were expressed as the mean \pm SEM. SPSS v17.0 (SPSS Inc., USA) was used to perform the statistical tests. The parametric test one-way analysis of variance (ANOVA) was used to determine significance among groups. The least significant difference test was used to evaluate the significant differences between two groups. Statistical significance difference was defined as $p<0.05$.

\section{Results \\ sRAGE increased the expression of IFN- $\gamma$ during $M I / R$ in mice}

To determine whether sRAGE regulated the expression of IFN- $\gamma$ in mice during MI/R, protein levels of IFN- $\gamma$ in the 
Fig. 1 sRAGE increased expression of IFN- $\gamma$ in $\mathrm{MI} / \mathrm{R}$ mice. a Levels of IFN- $\gamma$ in the serum of mice with or without sRAGE in sham- and MI/Rtreated mice. b IFN- $\gamma$ mRNA levels in hearts of sham- and MI/ R-treated mice with or without sRAGE. c Representative immunohistochemistry staining of IFN- $\gamma$ in hearts of sham- and MI/R-treated mice with or without sRAGE treatment (magnification: $\times 20$ ). Scale bar: $50 \mu \mathrm{m}$. d Representative quantification of IFN- $\gamma$-positive cells in heart tissue with or without sRAGE treatment during MI/R. Scale bar: $20 \mu \mathrm{m}$. Values are expressed as the mean \pm SEM $(n=6$ mice per group) $* \mathrm{p}<0.05 ; * * \mathrm{p}<0.01$ $* * * \mathrm{p}<0.001$
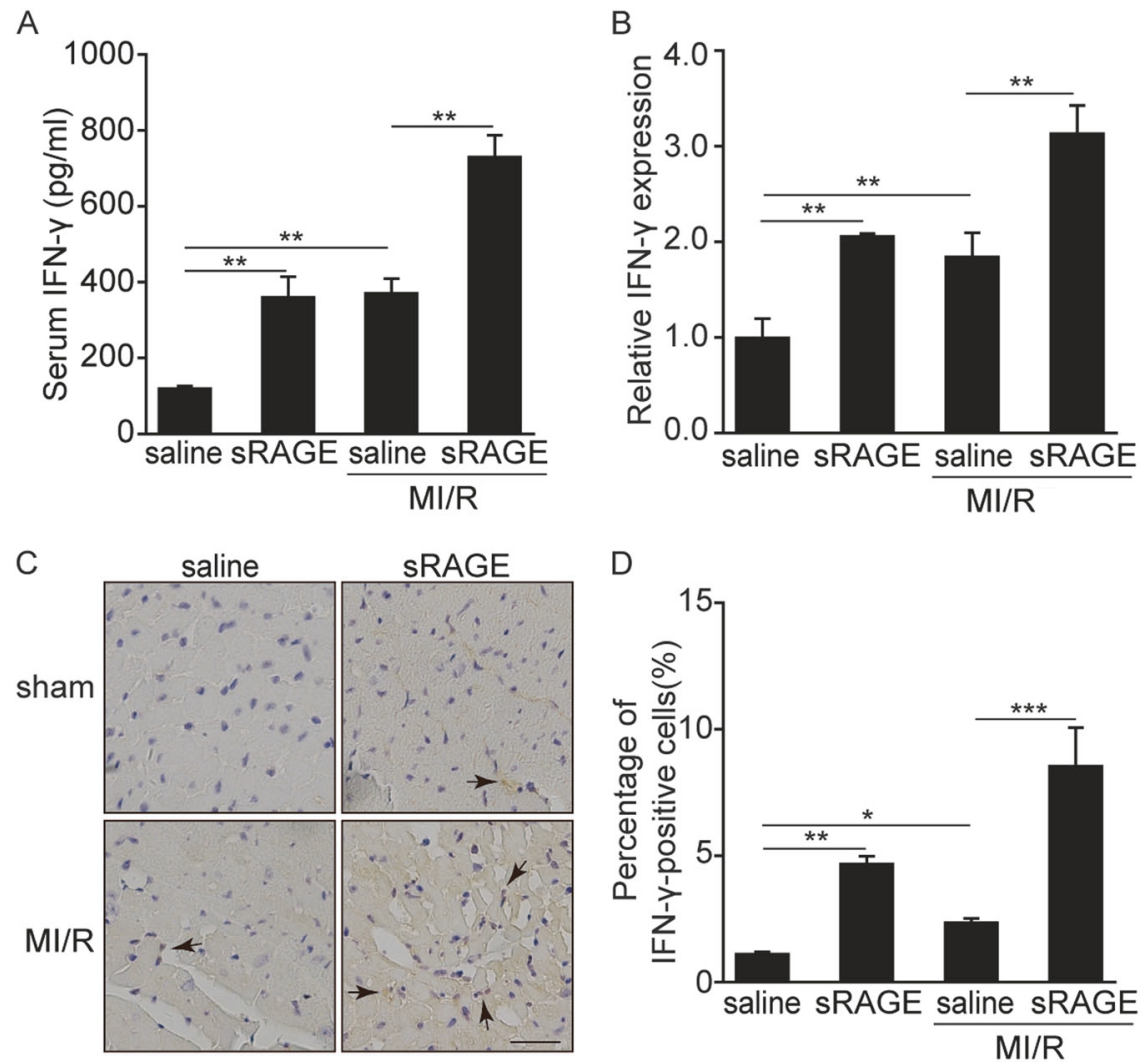

serum of mice and mRNA levels of IFN- $\gamma$ in mouse hearts were measured with or without sRAGE treatment. IFN- $\gamma$ in serum significantly increased from $119.7 \pm 7.6$ to 371.2 $\pm 38.7 \mathrm{pg} / \mathrm{ml}(p<0.01)$ during $\mathrm{MI} / \mathrm{R}$ and further increased to $730.0 \pm 58.2 \mathrm{pg} / \mathrm{ml}$ after sRAGE treatment $(p<0.01$, Fig. 1a). In addition, sRAGE increased IFN- $\gamma$ in sham mice serum from $119.7 \pm 7.6$ to $360.1 \pm 54.8 \mathrm{pg} / \mathrm{ml}(p<$ 0.01 , Fig. 1a). The real-time PCR results showed that the mRNA of IFN- $\gamma$ in mice heart increased $85.5 \%$ during $\mathrm{MI} / \mathrm{R}$ over levels in sham mice $(p<0.01$, Fig. 1b), whereas sRAGE increased IFN- $\gamma$ mRNA expression by $106.5 \%$ in sham mouse hearts $(p<0.01)$ and by $69.6 \%$ in $\mathrm{MI} / \mathrm{R}$ mouse hearts $(p<0.01$, Fig. 1b). Immunohistochemistry of IFN- $\gamma$ in mouse hearts showed that IFN- $\gamma$ increased 3.2-fold $(p<0.01)$ in sham mice and 2.6-fold $(p<0.001)$ in $\mathrm{MI} / \mathrm{R}$ mice after treatment with sRAGE. In addition, IFN- $\gamma$ immunohistochemistry showed that MI/R increased IFN- $\gamma$ expression 1.1-fold over levels in sham mice $(p<0.05$, Fig. 1c, d)

\section{Neutralization of IFN- $\gamma$ abolished the protective effect of SRAGE on MI/R-induced cardiac dysfunction}

To explore the effects of IFN- $\gamma$ on the improvement of cardiac function induced by sRAGE during MI/R, anti-IFN$\gamma$ antibodies were injected intraperitoneally before LAD ligation. Echocardiography revealed that MI/R significantly reduced LVEF from $65.6 \pm 4.64 \%$ to $23.3 \pm 4.41 \%(p<$ $0.01)$ and reduced FS from $35.6 \pm 3.52 \%$ to $12.0 \pm 2.00 \%$ $(p<0.001)$. However, sRAGE significantly increased LVEF from $23.3 \pm 4.41 \%$ to $46.9 \pm 8.50 \%(p<0.05)$ and increased FS from $12.0 \pm 2.00 \%$ to $30.6 \pm 5.71 \%(p<0.001)$ during $\mathrm{MI} / \mathrm{R}$. Moreover, blockade of IFN- $\gamma$ reduced LVEF from $46.9 \pm 8.50 \%$ to $30.1 \pm 4.80 \%(p<0.05)$ and reduced FS from $30.6 \pm 5.71 \%$ to $12.2 \pm 1.61 \%(p<0.01)$ in mice treated with sRAGE and MI/R (Table 1). In addition, MI/R increased LVEDV from $63.2 \pm 3.01$ to $88.6 \pm 4.76 \mu l(p<$ $0.05)$ and increased LVESV from $23.8 \pm 2.04$ to $65.6 \pm$ $7.16 \mu \mathrm{l}(p<0.01)$. However, sRAGE reduced LVEDV from $88.6 \pm 4.76$ to $60.8 \pm 9.52 \mu \mathrm{l}(p<0.05)$ and reduced LVESV from $65.6 \pm 7.16$ to $28.4 \pm 9.13 \mu \mathrm{l}(p<0.01)$ during MI/R. Moreover, pretreatment of IFN- $\gamma$ antibody increased LVEDV from $60.8 \pm 9.52$ to $105.8 \pm 9.71 \mu \mathrm{l}(p<0.001)$ and increased LVESV from $28.4 \pm 9.13$ to $95.8 \pm 11.1 \mu \mathrm{l}(p<$ 0.001 ) in mice treated with sRAGE and MI/R (Table 1).

\section{Neutralization of IFN- $\gamma$ reversed the inhibiting effect of SRAGE on MI/R injuries}

To explore the role of IFN- $\gamma$ in reducing infarct size by sRAGE during MI/R, infarct size was measured by Evans blue/TTC staining after IFN- $\gamma$ was neutralized. No significant differences in $\mathrm{AAR} /$ total ratio were observed among groups (Fig. 2a, b). Infarct size/AAR ratio was 
Table1 Echocardiography results for each group

\begin{tabular}{llllll}
\hline & sham & sRAGE & MI/R & $\begin{array}{l}\text { MI/R }+ \\
\text { sRAGE }\end{array}$ & $\begin{array}{l}\text { MI/R + sRAGE }+ \\
\text { anti-IFN- } \gamma\end{array}$ \\
\hline HR & $541.1 \pm$ & $527.8 \pm 17.05$ & $558.6 \pm 28.24$ & $571.0 \pm 12.73$ & $551.0 \pm 34.78$ \\
& 65.93 & & & & \\
LVEF $(\%)$ & $65.5 \pm 4.63$ & $65.2 \pm 3.95$ & $23.3 \pm 4.41^{* *}$ & $46.9 \pm 8.50^{\#}$ & $30.1 \pm 4.80^{\&}$ \\
FS $(\%)$ & $35.6 \pm 3.52$ & $35.0 \pm 2.94$ & $12.0 \pm 2.00^{* * *}$ & $30.6 \pm 5.71^{\# \# \#}$ & $12.2 \pm 1.61^{\& \&}$ \\
CO $(\mathrm{mL} / \mathrm{min})$ & $20.0 \pm 2.43$ & $18.7 \pm 1.03$ & $13.6 \pm 1.39^{*}$ & $17.0 \pm 2.40$ & $13.9 \pm 2.10$ \\
SV $(\mu \mathrm{L})$ & $36.9 \pm 1.43$ & $35.6 \pm 3.10$ & $24.4 \pm 2.53^{*}$ & $30.2 \pm 4.81$ & $22.7 \pm 2.27$ \\
LVM $(\mathrm{mg})$ & $63.3 \pm 3.86$ & $66.9 \pm 1.09$ & $68.0 \pm 2.15$ & $72.1 \pm 4.07$ & $67.4 \pm 5.86^{\&}$ \\
LVEDV $(\mu \mathrm{L})$ & $63.2 \pm 3.01$ & $56.8 \pm 1.46$ & $88.6 \pm 4.76^{*}$ & $60.8 \pm 9.52^{\#}$ & $105.8 \pm 9.71^{\& \& \&}$ \\
LVESV $(\mu \mathrm{L})$ & $23.8 \pm 2.04$ & $20.0 \pm 0.01$ & $65.6 \pm 7.16^{* *}$ & $28.4 \pm 9.13^{\# \#}$ & $95.8 \pm 11.1^{\& \& \&}$ \\
LVEDD $(\mathrm{mm})$ & $4.0 \pm 0.24$ & $3.6 \pm 0.04$ & $4.2 \pm 0.29$ & $3.8 \pm 0.27$ & $4.3 \pm 0.29$ \\
LVESD $(\mathrm{mm})$ & $2.9 \pm 0.33$ & $2.3 \pm 0.08$ & $3.9 \pm 0.20$ & $2.9 \pm 0.36$ & $3.8 \pm 0.34$ \\
\hline
\end{tabular}

All the values were expressed as mean \pm SEM and calculated from at least five mice in each group

$M I / R$ myocardial ischemia/reperfusion, $H R$ heart rate, $L V E F$ left ventricular ejection fraction, $F S$ fractional shortening, $C O$ cardiac output, $S V$ stroke volume, $L V M$ left ventricular mass, $L V E D V$ left ventricular enddiastolic volume, $L V E S V$ left ventricular end-systolic volume, $L V E D D$ left ventricular end-diastolic diameter, LVESD left ventricular end-systolic diameter

${ }^{*} p<0.05$ vs sham; $* * p<0.01$ vs sham; $* * * p<0.001$ vs sham; ${ }^{*} p<0.05$ vs MI/R; ${ }^{\# \#} p<0.01$ vs MI/R;

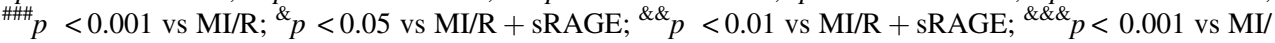
$\mathrm{R}+\mathrm{sRAGE}$ significantly reduced by $58.2 \%$ with sRAGE treatment during MI/R $(p<0.05$, Fig. 2a-c), whereas blockade of IFN- $\gamma$ before sRAGE treatment increased infarct size/AAR ratio by $156.7 \%$ compared with mice treated with sRAGE alone during $\mathrm{MI} / \mathrm{R}(p<0.05$, Fig. 2a-c).

To test the role of IFN- $\gamma$ in inhibiting apoptosis by sRAGE during MI/R, TUNEL staining and caspase-3 expression were measured in mouse hearts after IFN- $\gamma$ was blocked. MI/R led to an increase of TUNEL-positive cells and cleaved caspase- 3 in mouse hearts, whereas sRAGE reduced TUNEL-positive cells by $48.0 \%(p<0.05$, Fig. 2 d, e) and reduced cleaved caspase- 3 by $32.5 \%(p<$ 0.05 , Fig. $2 \mathrm{~d}-\mathrm{g}$ ) after MI/R. However, blockade of IFN- $\gamma$ before sRAGE treatment induced a $204.7 \%$ increase of TUNEL-positive cells $(p<0.001$, Fig. 2 d, e) and a $79.1 \%$ increase of cleaved caspase-3 $(p<0.05$, Fig. $2 \mathrm{~d}-\mathrm{g})$ compared with the mice treated with sRAGE during MI/R.

\section{Neutralization of IFN- $\gamma$ inhibited the upregulating effect of SRAGE on proteasomes during MI/R}

To explore whether IFN- $\gamma$ influenced the upregulation of proteasome subunits induced by sRAGE during MI/R, the expression of immunoproteasome subunits and proteolytic activities of proteasome were tested after blockade of IFN- $\gamma$. The expression of immunoproteasome subunits, including $\beta 1 \mathrm{i}, \beta 2 \mathrm{i}$ and $\beta 5 \mathrm{i}$ were decreased by $39.0 \%(p<0.05), 29.5 \%$ $(p<0.05)$ and $44.6 \%(p<0.05)$ during MI/R compared with sham mice, respectively, whereas sRAGE markedly increased the expression of $\beta 1$ by $27.2 \%(p<0.05)$ and of
35 i by $92.1 \%(p<0.01)$ after MI/R (Fig. 3a-d). However, sRAGE had no effect on the expression of $\beta 2 \mathrm{i}$ during MI/R $(p>0.05$, Fig. $3 \mathrm{a}-\mathrm{c})$. Blockade of IFN- $\gamma$ using anti-IFN- $\gamma$ antibody before sRAGE treatment reduced expression of $\beta 1 \mathrm{i}, \beta 2 \mathrm{i}$ and $\beta 5 \mathrm{i}$ by $40.7 \%(p<0.05), 38.7 \%(p<0.05)$ and $49.6 \%(p<0.01)$, respectively, during MI/R (Fig. 3a-d). In addition, blockade of IFN- $\gamma$ before sRAGE treatment also reduced chymotrypsin-like activity by $15.8 \%(p<0.05)$ during $\mathrm{MI} / \mathrm{R}$ but did not change caspase-like and trypsinlike proteolytic activities (Fig. 3e).

\section{Neutralization of IFN- $\gamma$ abolished the signaling pathways induced by SRAGE}

To determine whether IFN- $\gamma$ was involved in mediating the signaling pathways regulated by UPS during MI/R, p53, p38 and JNK1/2 were measured by western blot after IFN- $\gamma$ was neutralized. Phosphorylated p38, JNK1 and JNK2, as well as the expression of $\mathrm{p} 53$, were increased 1.56-fold $(p<$ $0.001), 3.51$-fold $(p<0.001), 1.39$-fold $(p<0.001)$ and 0.67 -fold $(p<0.001)$, respectively, during $\mathrm{MI} / \mathrm{R}$, whereas sRAGE reduced phosphorylated p38, JNK1 and JNK2, as well as the expression of p53, by $69.5 \%(p<0.001), 62.2 \%$ $(p<0.01), 26.9 \% \quad(p<0.01)$ and $56.1 \% \quad(p<0.001)$, respectively, after MI/R (Fig. 4a-e). Blockade of IFN- $\gamma$ before sRAGE treatment significantly decreased phosphorylated p38 and JNK1 and the expression of p53 by 93.8\% $(p<0.05), 72.4 \%(p<0.05)$ and $104.2 \%(p<0.001)$, respectively, compared with mice treated with sRAGE and MI/R (Fig. 4a-e). However, IFN- $\gamma$ antibody had no effects 

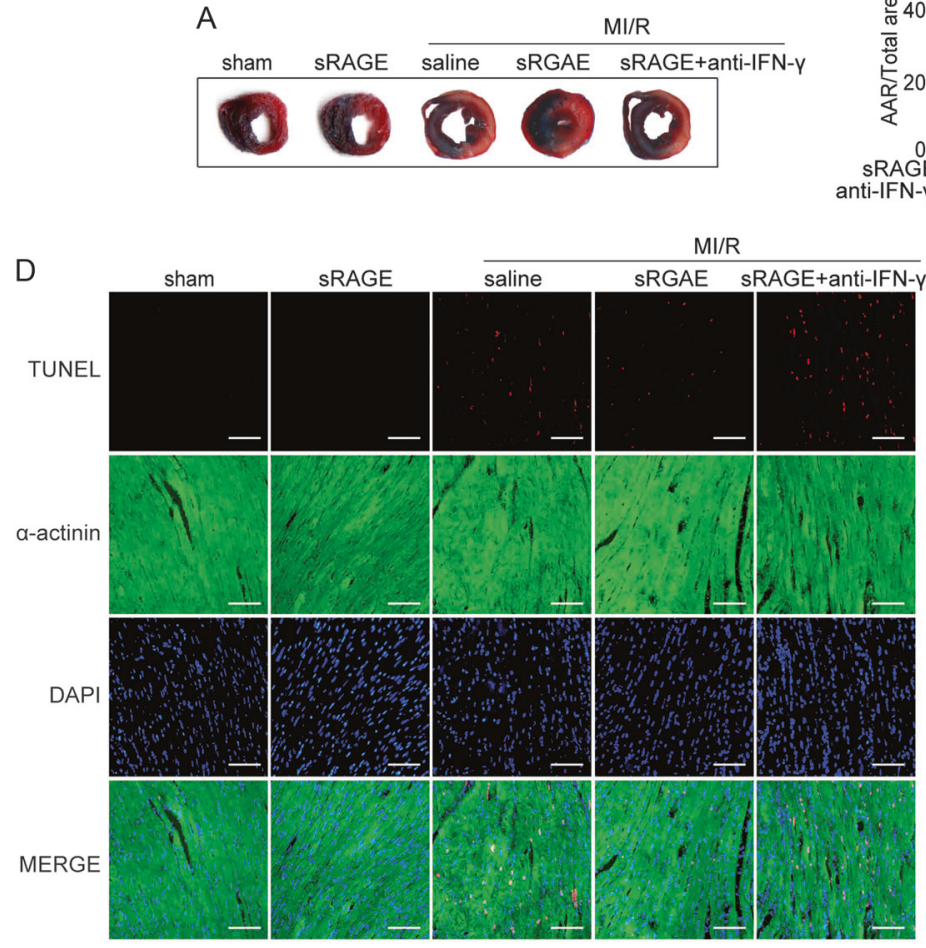

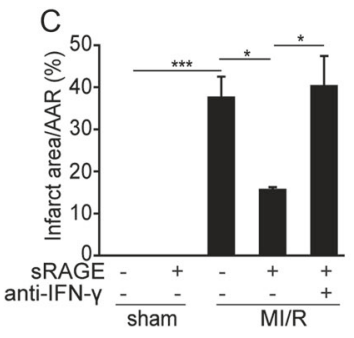

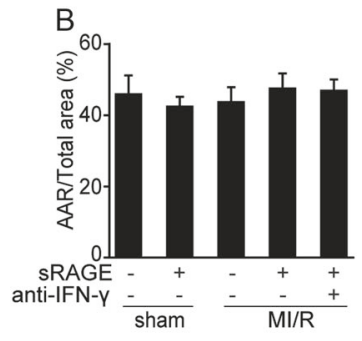
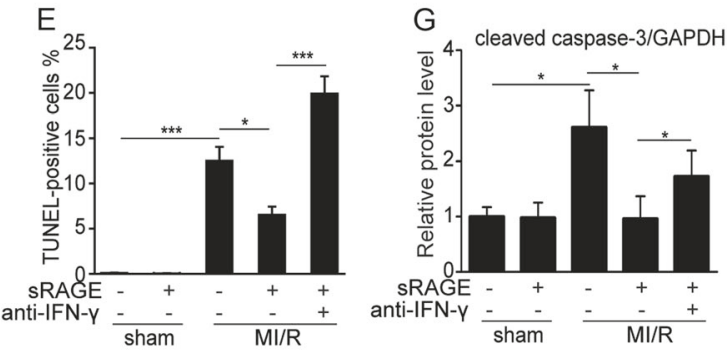

$\mathrm{F}$

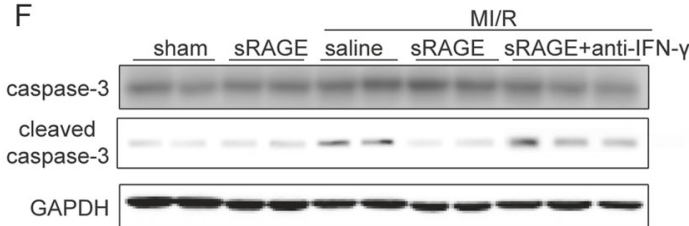

Fig. 2 Neutralization of IFN- $\gamma$ reversed the inhibiting effects of sRAGE on MI/R-induced injuries. a Representative images of Evans blue and TTC staining in hearts. The blue area indicates viable tissue. The white area indicates infarct tissue. The area of red plus white indicates AAR. b Quantification of AAR/total area ratio in each group. c Quantification of infarct area/AAR ratio in each group. d Representative image of TUNEL and $\alpha$-actinin staining in mouse hearts with

on the phosphorylation of JNK2 that was inhibited by sRAGE during MI/R ( $p>0.05$, Fig. $4 d)$.

\section{Knockdown of $\beta 5 i$ attenuated the antiapoptotic effects of sRAGE during $H / R$}

To further explore the role of $\beta 1 \mathrm{i}$ and $\beta 5 \mathrm{i}$ subunits in sRAGE-inhibited apoptosis in H/R-treated cardiomyocytes, Ad-si $\beta 1 i$ and Ad-si $\beta 5 i$ were transfected into H/R-treated cardiomyocytes. Knockdown of $\beta 5 \mathrm{i}$ reversed the antiapoptosis effects of sRAGE in H/R-treated cardiomyocytes: TUNEL-positive cells increased by $93.6 \%(p<0.01$, Fig. $5 \mathrm{a}, \mathrm{b})$ and cleaved caspase- 3 increased by $84.4 \%(p<$ 0.05 , Fig. 5c, d) compared with sRAGE and H/R-treated cardiomyocytes. However, knockdown of $\beta 1 \mathrm{i}$ did not affect the antiapoptosis effect of sRAGE during H/R (supplementary Figure S4).

To elucidate the molecular mechanism of $\beta 5 \mathrm{i}$ in mediating the inhibiting effects of sRAGE on H/R-induced apoptosis, apoptosis signaling pathways, including p38, JNK1/2 and p53 were examined after knockdown of $\beta 5 \mathrm{i}$ in or without sRAGE and anti-IFN- $\gamma$ antibody treatment. Magnification: $\times 20$. Scale bar: $50 \mu \mathrm{m}$. e Quantification of TUNEL-positive cells in fold-change over sham mice in each group. $\mathbf{f}$ Representative image of western blot for caspase-3 in mouse hearts with or without sRAGE and anti-IFN-antibody treatment. g Quantification of the relative expression of caspase- 3 in mouse hearts. Values are expressed as the mean $\pm \operatorname{SEM}(n=7$ mice per group). $* p<0.05 ; * * * p<0.001$

cardiomyocytes. Knockdown of $\beta 5 \mathrm{i}$ with Ad-si $\beta 5 \mathrm{i}$ in cardiomyocytes increased expression of p53 144.3\% compared with sRAGE- and H/R-treated cardiomyocytes $(p<0.05$, Fig. 6a-c). However, knockdown of $\beta 5 \mathrm{i}$ did not affect phosphorylated p38, JNK1 and JNK2 that were inhibited by sRAGE during H/R (Fig. 6a-e). Furthermore, to confirm whether $\mathrm{p} 53$ decreased due to increased degradation by $\beta 5 \mathrm{i}$ that was upregulated by overexpression of sRAGE in cardiomyocytes, the ubiquitination of p53 was measured with or without Ad-sRAGE or Ad-siß5i. Overexpression of sRAGE reduced the accumulation of ubiquitinated p53 during $H / R$, whereas knockdown of $\beta 5$ i markedly inhibited this effect (Fig. 6f).

\section{sRAGE inhibited long-term injuries induced by MI/R}

To evaluate whether or not the protective effects of sRAGE were sustained, heart function, cardiac apoptosis and morphological changes in hearts were observed after reperfusion for 14 days. Consistent with previous studies, sRAGE meliorated cardiac dysfunction (supplementary Table 1) and 


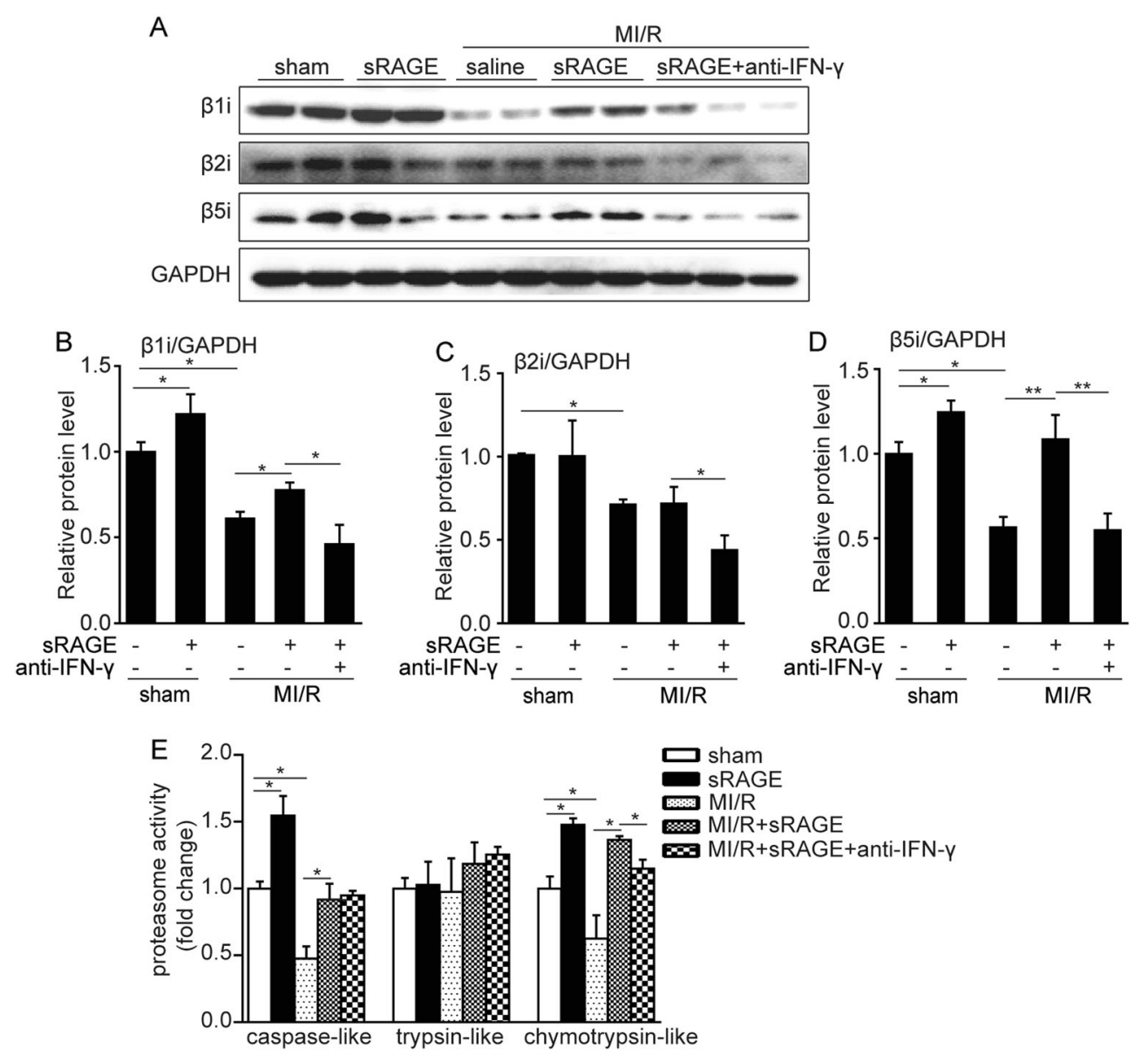

Fig. 3 Neutralization of IFN- $\gamma$ abolished the upregulating effect of sRAGE on proteasome subunits in MI/R-treated hearts. a Representative images of western blot for $\beta 1 \mathrm{i}, \beta 2 \mathrm{i}$ and $\beta 5 \mathrm{i}$ in mouse hearts with or without sRAGE and anti-IFN-antibody treatment. b Quantification of the relative expression of $\beta 1 \mathrm{i}$ in mouse hearts. c Quantification of relative expression of $\beta 2 \mathrm{i}$ in mouse hearts. $\mathbf{d}$ Quantification of

significantly alleviated remodeling and apoptosis in hearts (supplementary Figure S5A-D) after reperfusion for 14 days. These results suggested that the cardioprotection of sRAGE was sustained not only for $24 \mathrm{~h}$ but also for longer terms.

\section{Discussion}

This work demonstrated that protective effects of sRAGE were mediated by IFN- $\gamma$ during $\mathrm{MI} / \mathrm{R}$, associated with upregulation of immunoproteasome subunits in mouse heart. The results showed that sRAGE increased the expression of IFN- $\gamma$ in mouse hearts during $\mathrm{MI} / \mathrm{R}$ and blocking IFN- $\gamma$ significantly abolished the improvement of cardiac function, as well as the inhibition of apoptosis induced by sRAGE during MI/R. Moreover, blockade of IFN- $\gamma$ suppressed the upregulation of proteasome induced by sRAGE after $\mathrm{MI} / \mathrm{R}$, confirmed by the decreased the relative expression of $\beta 5$ i in mice hearts. e Quantification of the relative caspase-like, trypsin-like and chymotrypsin-like activities in mouse hearts with or without sRAGE and anti-IFN-antibody treatment. Values are expressed as the mean \pm SEM $(n=6$ mice per group). $* p<0.05 ; * * p<0.01$

expression of immunoproteasome subunits and chymotrypsin-like activity. In addition, deficiency of $\beta 5 \mathrm{i}$, rather than of $\beta 1$, reversed the inhibition of apoptosis and the promotion of p53 degradation induced by sRAGE during H/R in cardiomyocytes. Furthermore, sRAGE displayed long-term protective effects on $M I / R$ injuries in the heart in addition to the short-term effects. Thus, this work demonstrated that IFN- $\gamma$ was involved in the protective effects of sRAGE on MI/R-induced injuries, correlating with the increased assembly of the immunoproteasome and resulting in the degradation of $\mathrm{p} 53$, possibly promoting the translation of sRAGE into clinical medicine.

Previous studies demonstrated that SRAGE induced production of interleukin- 6 , tumor necrosis factor- $\alpha$ and IFN- $\gamma$ in mouse splenocytes $[18,19]$. In the present study, intramyocardial injection of recombinant sRAGE protein increased levels of IFN- $\gamma$ both in heart tissues and in mice serum during MI/R (Fig. 1). To confirm the effect of sRAGE on the expression of IFN- $\gamma$, human serum albumin was used 

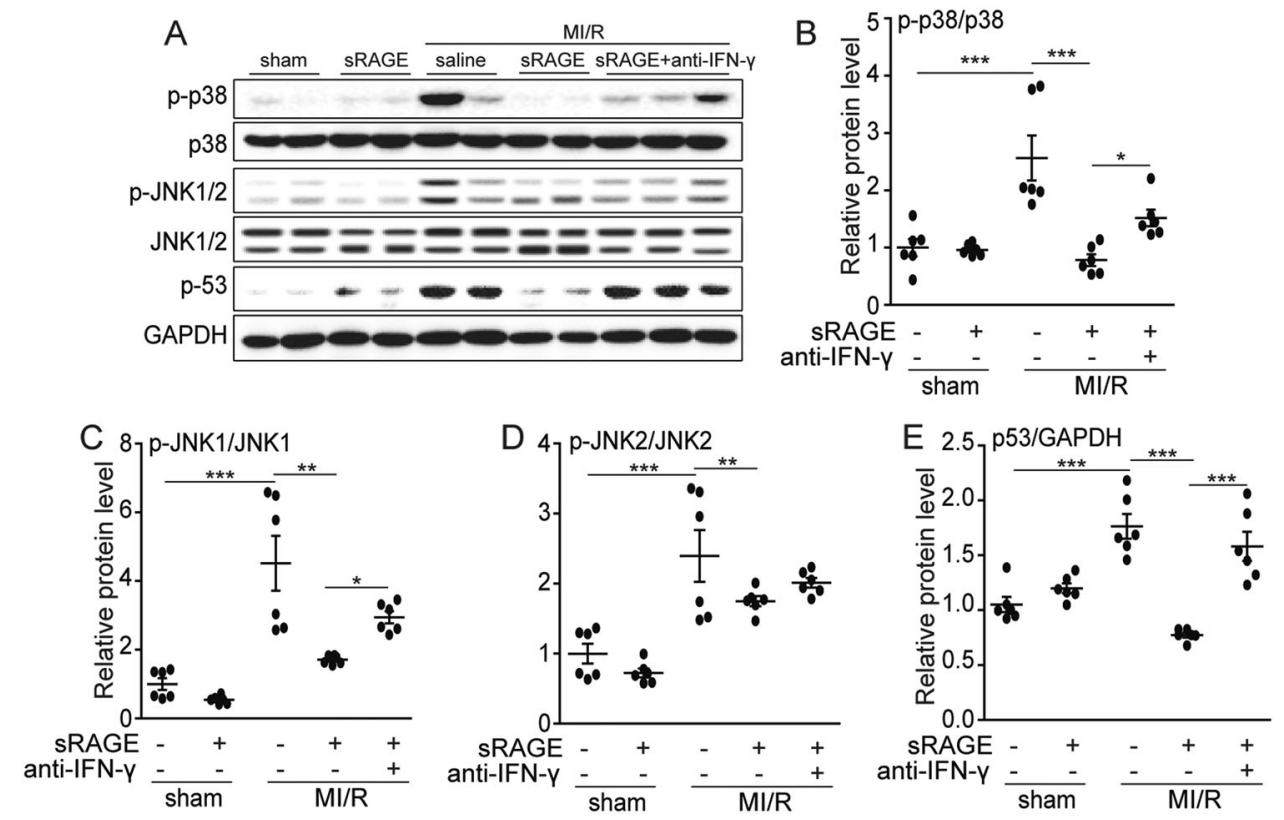

Fig. 4 Neutralization of IFN- $\gamma$ reversed the inhibiting effects of sRAGE on signaling molecules in MI/R-treated hearts. a Representative image of western blot for phosphorylated p38, p38, phosphorylated JNK1/2, JNK1/2 and p53 in mouse hearts with or without sRAGE and anti-IFN-antibody treatment. b Quantification of the relative expression of phosphorylated $\mathrm{p} 38 / \mathrm{p} 38$ in mice hearts.

as a vehicle to measure the expression of IFN- $\gamma$ in mice serum and IFN- $\gamma$ mRNA in mouse hearts (because the recombinant sRAGE protein in this study was from a human source) before and after MI/R. Expression of IFN- $\gamma$ in mice serum and heart tissue did not show any significant difference between mice treated with human serum albumin or saline (supplementary Figure S1). These results suggested that the increase in IFN- $\gamma$ was attributed to the effects of sRAGE but not those of serum albumin. IFN- $\gamma$, the only member of the type II family of IFNs, was secreted by inflammatory cells including macrophages, lymphocytes and neutrophils [27]. The results in this work showed that sRAGE induced macrophages in the heart to produce IFN- $\gamma$, as shown by increased numbers of IFN- $\gamma^{+} / \mathrm{CD}^{+} 8^{+}$macrophages compared with IFN- $\gamma^{+} / \mathrm{CD}^{+}$lymphocytes and IFN$\gamma^{+} / \mathrm{Ly}_{6 \mathrm{G}^{+}}$neutrophils in double-immunofluorescent staining in hearts (Fig. 1 and supplementary Figure S2). Contrary to our expectations, the results also indicated that sRAGE increased the infiltration of macrophages, appearing to play a pro-inflammatory role during MI/R. Macrophages were derived from monocytes and differentiated into two phenotypes: classically activated macrophages (M1) and alternatively activated macrophages (M2) [28]. M1-macrophages were thought to be pro-inflammatory, dominating the early phase of myocardial ischemia processes [29-31], whereas M2-macrophages were proved to prevent heart or kidney from ischemia/reperfusion injuries $[32,33]$. Previous studies c Quantification of the relative expression of phosphorylated JNK1/ JNK1 in mouse hearts. d Quantification of the relative expression of phosphorylated JNK2/JNK2 in mouse hearts. e Quantification of the relative expression of p53 in mouse hearts. Values are expressed as the mean \pm SEM ( $n=6$ mice per group). ${ }^{*} p<0.05 ; * * \mathrm{p}<0.01$; $* * * p<0.001$

demonstrated that sRAGE directly bound to monocytes and promoted their differentiation to macrophages [34]. To analyze the phenotype of macrophages recruited by sRAGE in mouse hearts, immunohistochemistry of iNOS and CD206 was used to reveal the M1-macrophages and M2-macrophages, respectively. Both M1-macrophages and M2-macrophages were increased during MI/R. However, M2-macrophages were further increased, whereas M1macrophages were reduced after sRAGE treatment in MI/ $\mathrm{R}$ mice hearts (supplementary Figure S3). Therefore, it could be supposed that sRAGE might facilitate differentiation of monocytes into M2-macrophage to protect the heart against injuries during $\mathrm{MI} / \mathrm{R}$, a finding that should be verified in future investigations.

It was reported that IFN- $\gamma$ was a critical factor in modulating the proteasome: the constitutive subunits in the $20 \mathrm{~s}$ proteasome were replaced by the three inducible subunits, including $\beta 1 \mathrm{i}, \beta 2 \mathrm{i}$ and $\beta 5 \mathrm{i}$ when IFN- $\gamma$ was exposed to the cells $[16,35]$. In the present study, the increase of $\beta 1 \mathrm{i}$ and $\beta 5 \mathrm{i}$ was accompanied by increased IFN- $\gamma$ in the serum and heart of mice with sRAGE treatment, whereas no such effects were observed in $\mathrm{MI} / \mathrm{R}$ mice without sRAGE treatment (Fig. 3). These results suggested that IFN- $\gamma$ was not the only factor inducing expression of proteasome subunits; there are still undefined factors accompanying IFN- $\gamma$ to mediate the effects of sRAGE on MI/R mice. 

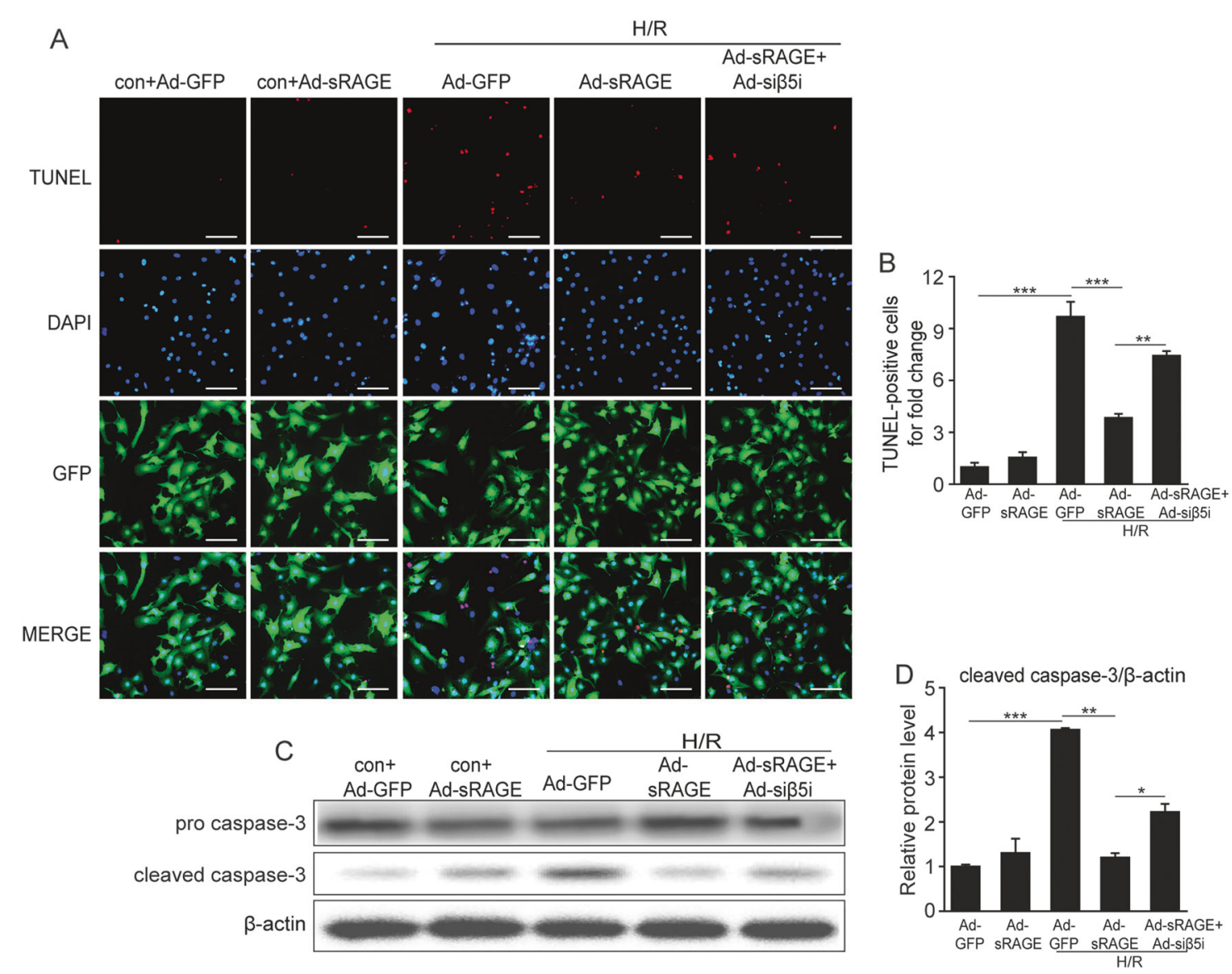

Fig. 5 Knockdown $\beta 5 i$ abolished the inhibiting effects of sRAGE on H/R-induced apoptosis in cultured cardiomyocytes. Neonatal rat cardiomyocytes were infected with adenovirus expressing GFP (AdGFP), sRAGE (Ad-sRAGE) or $\beta 5 \mathrm{i}$ shRNA (Ad-si $\beta 5 \mathrm{i}$ ) for at least $24 \mathrm{~h}$ and then stimulated H/R. a Representative image of TUNEL staining in cardiomyocytes in each group. Magnification: $\times 20$. Scale bar: 50

To confirm the effects of IFN- $\gamma$ on the expression of the proteasome in sRAGE-treated hearts, the neutralizing antibody of IFN- $\gamma$ was applied to mice. The effects of sRAGE on increasing $\beta 1 \mathrm{i}$ and $\beta 5 \mathrm{i}$ during $\mathrm{MI} / \mathrm{R}$ were abolished by the antibody (Fig. 3), consistent with a previous report where there was a reduction of $\beta 5 \mathrm{i}$ in IFN- $\gamma^{-1-}$ mice hearts [36]. Interestingly, neutralization of IFN- $\gamma$ only led to the reduction of chymotrypsin-like activity rather than to caspase-like and trypsin-like activities, in agreement with the report that both $\beta 1 \mathrm{i}$ and $\beta 5 \mathrm{i}$ subunits exerted chymotrypsin-like activity [12].

UPS was the major nonlysosome system for degradation of misfolded proteins and it played an important role in MI/ R. Substantial evidence has supported the notion that proteasome insufficiency during $\mathrm{MI} / \mathrm{R}$ led to severe tissue damage $[15,37,38]$, whereas enhancement of cardiac proteasome proteolytic activities resulted in increased cellular survival rates in $\mathrm{MI} / \mathrm{R}$ in mice [39]. Consistent with our previous study [10], the present work confirmed that sRAGE abolished the reduction of $\beta$-subunits in the $\mu \mathrm{m}$. b Quantification of TUNEL-positive cells in fold-change over the control group. $\mathbf{c}$ Representative image of western blot for caspase-3 in cardiomyocytes for each group. d Quantification of the relative expression of caspase-3 in cardiomyocytes. Values are expressed as the mean \pm SEM from three independent experiments. $* p<0.05$; $* * p<0.01 ; * * * p<0.001$

proteasome and ameliorated $\mathrm{MI} / \mathrm{R}$ injuries in hearts. Blockade of IFN- $\gamma$ reversed the upregulation of proteasome proteolytic activities induced by sRAGE during MI/R, accompanied by abolition of the protective effects of sRAGE on MI/R-induced injuries (the deterioration of cardiac function and exacerbation of infarct size and apoptosis, Table 1 and Fig. 2). Therefore, proteasome activities induced by IFN- $\gamma$ might mediate the protective effects of sRAGE during MI/R.

During MI/R, the proteasome was involved in degradation not only of misfolded and damaged proteins but also of cell signaling factors including JNK, p38 and p53 that would lead to apoptosis in cells [40]. In the present study, sRAGE decreased phosphorylation of $\mathrm{p} 38$, as well as the expression of p53 during MI/R, which was abolished when proteasome activities were downregulated by the blockade of IFN- $\gamma$. sRAGE also inhibited MI/Rinduced phosphorylation of JNK1 and JNK2. However, blockade of IFN- $\gamma$ reversed the inhibiting effects of sRAGE on JNK1 phosphorylation during MI/R, but not 

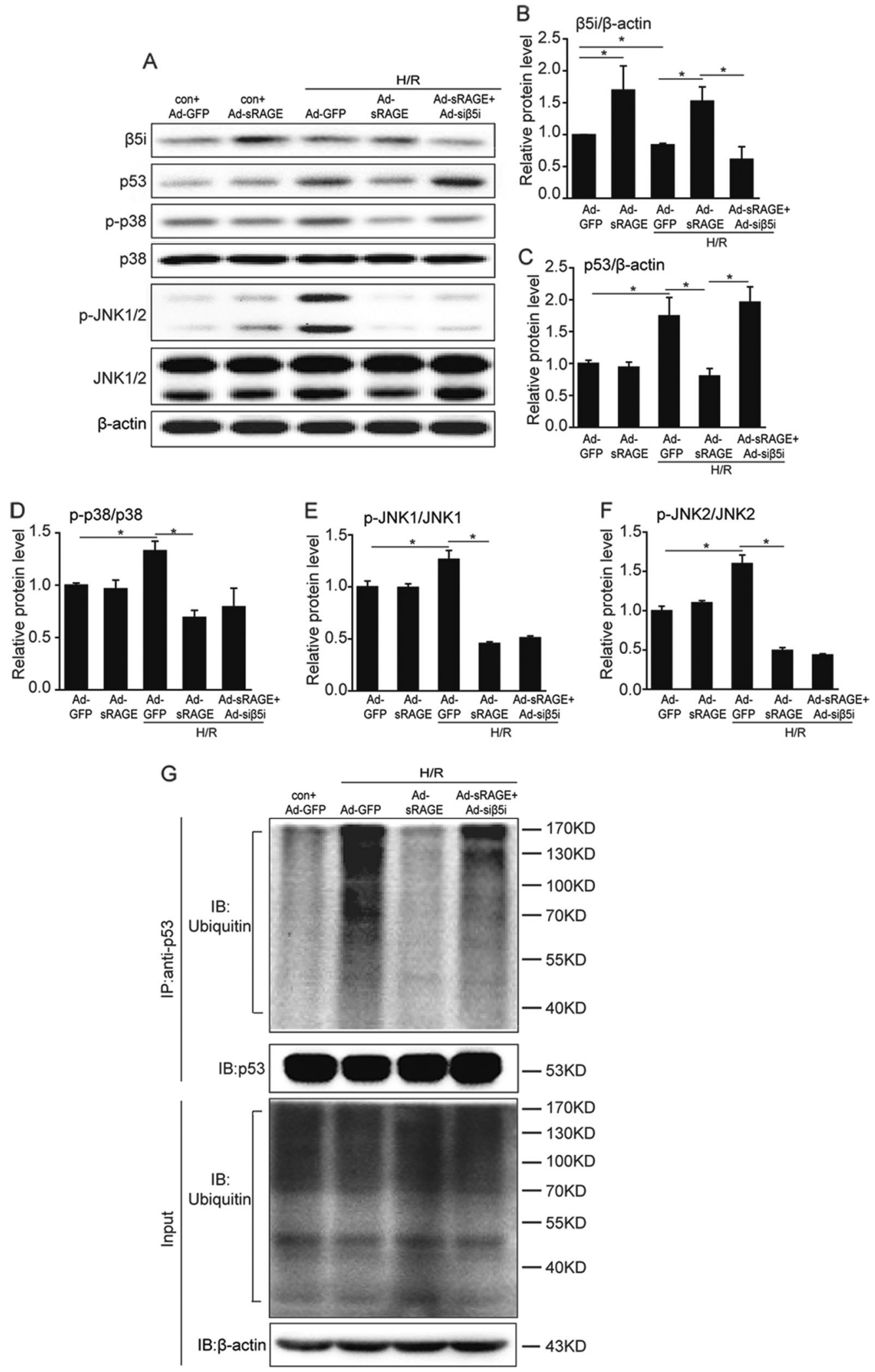

on JNK2 phosphorylation (Fig. 4c, d). These results suggested that decreased p38, p53 and JNK1 induced by sRAGE in $\mathrm{MI} / \mathrm{R}$ injuries in heart might be mediated by
IFN- $\gamma$-associated proteasome expression. As opposed to the pro-apoptotic effects of JNK1, JNK2 showed no such effects during H/R in vitro [41]; therefore, JNK2 may not 
Fig. 6 Knockdown of $\beta 5$ i abolished the inhibiting effects of sRAGE on signaling molecules in H/R-treated cardiomyocytes. a Representative image of western blot for the $\beta 5 \mathrm{i}$ subunit, phosphorylated p38, p38, phosphorylated JNK1/2, JNK1/2 and p53 in cardiomyocytes. b Quantification of the relative expression of $\beta 5 \mathrm{i}$ in cardiomyocytes. c Quantification of the relative expression of p53 in cardiomyocytes. d Quantification of the relative expression of phosphorylated p38/p38 in cardiomyocytes. e Quantification of the relative expression of phosphorylated JNK1/JNK1 in cardiomyocytes. f Quantification of the relative expression of phosphorylated JNK2/ JNK2 in cardiomyocytes. g Representative images of ubiquitinated p53 in each group. Values are expressed as the mean \pm SEM from three independent experiments. $* p<0.05$

be involved in the antiapoptotic effects of sRAGE in MI/R injuries.

Previous studies reported that either $\beta 1 \mathrm{i}$ or $\beta 5 \mathrm{i}$ deficiency aggravated MI/R injuries in animals [38, 42, 43]. The present study showed that sRAGE significantly increased the expression of $\beta 1 \mathrm{i}$ and $\beta 5 \mathrm{i}$, contributing to increased chymotrypsin-like proteasome activity in $\mathrm{MI} / \mathrm{R}$ hearts. A question remained as to which subunit was involved in the protective effect of sRAGE on cardiomyocytes during MI/ R. A deficiency of $\beta 5 \mathrm{i}$ in cardiomyocytes abolished the inhibiting effects of sRAGE on apoptosis in H/R-treated cardiomyocytes (Fig. 5), whereas deficiency of $\beta 1$ i did not show such effects (supplementary Figure S4). Furthermore, deficiency of $\beta 5$ i significantly increased the expression of p53 in H/R-treated cardiomyocytes other than JNK and p38 with or without sRAGE (Fig. 6). These results suggested that $\beta 5$ i mediated the protective effects of sRAGE on MI/Rinduced apoptosis in cardiomyocytes by inducing p53 degradation.

To verify that sRAGE decreased p53 by degrading ubiquitinated p53, p53 ubiquitination was measured in cardiomyocytes. Overexpression of sRAGE reduced the accumulation of ubiquitinated p53 in cardiomyocytes during $\mathrm{H} / \mathrm{R}$, an effect that was abolished by the absence of $\beta 5 \mathrm{i}$. These results indicated that p53 was degraded by the $\beta 5 \mathrm{i}$ immunoproteasome that was induced by sRAGE to decrease apoptosis in $\mathrm{H} / \mathrm{R}$ cardiomyocytes.

In addition, sRAGE alleviated cardiac dysfunction, apoptosis and fibrosis after reperfusion for 14 days, suggesting that the protective effects of sRAGE were both short-term and long-term effects.

For the first time, this study demonstrated that sRAGE protected the heart against $\mathrm{MI} / \mathrm{R}$ injuries by increasing the expression of IFN- $\gamma$ that facilitated expression of immunoproteasome subunit $\beta 5$ i. In addition, $\beta 5 \mathrm{i}$ might be the crucial subunit mediated by sRAGE to promote the degradation of p53, resulting in decreased apoptosis in MI/Rtreated hearts. These findings provided a novel mechanism of sRAGE in inhibiting cardiac apoptosis induced by MI/R, which is possibly beneficial for accelerating the use of sRAGE in clinical therapeutics.
Acknowledgements This work was supported by the National Natural Science Foundation of China (grant no. 81570321, 81370313, 30801217), the Beijing Health System High Level Health Technical Personnel Training Program (grant no. 2013-3-046) and the Beijing Nova Program (grant no. 2010B050).

\section{Compliance with ethical standards}

Conflict of interest The authors declare that they have no conflict of interest.

\section{References}

1. Patel SS, Rosenberg AH, Studier FW, Johnson KA. Large scale purification and biochemical characterization of $\mathrm{T} 7$ primase/helicase proteins. Evidence for homodimer and heterodimer formation. J Biol Chem 1992;26721:15013-21.

2. Schmidt AM, Vianna M, Gerlach M, Brett J, Ryan J, Kao J, et al. Isolation and characterization of two binding proteins for advanced glycosylation end products from bovine lung which are present on the endothelial cell surface. J Biol Chem 1992;26721:14987-97.

3. Raucci A, Cugusi S, Antonelli A, Barabino SM, Monti L, Bierhaus A, et al. A soluble form of the receptor for advanced glycation endproducts (RAGE) is produced by proteolytic cleavage of the membrane-bound form by the sheddase a disintegrin and metalloprotease 10 (ADAM10). FASEB J 2008;2210:3716-27.

4. Yan SF, Ramasamy R, Schmidt AM. Soluble RAGE: therapy and biomarker in unraveling the RAGE axis in chronic disease and aging. Biochem Pharmacol 2010;7910:1379-86.

5. Shang L, Ananthakrishnan R, Li Q, Quadri N, Abdillahi M, Zhu $\mathrm{Z}$, et al. RAGE modulates hypoxia/reoxygenation injury in adult murine cardiomyocytes via JNK and GSK-3beta signaling pathways. PLoS ONE 2010;54:e10092.

6. Aleshin A, Ananthakrishnan R, Li Q, Rosario R, Lu Y, Qu W, et al. RAGE modulates myocardial injury consequent to LAD infarction via impact on JNK and STAT signaling in a murine model. Am J Physiol Heart Circ Physiol 2008;2944:H1823-32.

7. $\mathrm{Ku} \mathrm{SH}$, Hong J, Moon HH, Jeong JH, Mok H, Park S, et al. Deoxycholic acid-modified polyethylenimine based nanocarriers for RAGE siRNA therapy in acute myocardial infarction. Arch Pharm Res 2015;387:1317-24.

8. Jiang X, Guo CX, Zeng XJ, Li HH, Chen BX, Du FH. A soluble receptor for advanced glycation end-products inhibits myocardial apoptosis induced by ischemia/reperfusion via the JAK2/STAT3 pathway. Apoptosis 2015;208:1033-47.

9. Guo C, Zeng X, Song J, Zhang M, Wang H, Xu X, et al. A soluble receptor for advanced glycation end-products inhibits hypoxia/ reoxygenation-induced apoptosis in rat cardiomyocytes via the mitochondrial pathway. Int J Mol Sci 2012;139:11923-40.

10. Guo CX, Jiang X, Zeng XJ, Wang HX, Li HH, Du FH, et al. Soluble receptor for advanced glycation end-products protects against ischemia/reperfusion-induced myocardial apoptosis via regulating the ubiquitin proteasome system. Free Radic Biol Med 2016;94:17-26.

11. Kleiger G, Mayor T. Perilous journey: a tour of the ubiquitinproteasome system. Trends Cell Biol 2014;246:352-9.

12. Angeles A, Fung G, Luo H. Immune and non-immune functions of the immunoproteasome. Front Biosci (Landmark Ed) 2012;17:1904-16.

13. Li N, Wang HX, Han QY, Li WJ, Zhang YL, Du J, et al. Activation of the cardiac proteasome promotes angiotension IIinduced hypertrophy by down-regulation of ATRAP. J Mol Cell Cardiol 2015;79:303-14. 
14. Ren H, Li F, Tian C, Nie H, Wang L, Li HH, et al. Inhibition of Proteasome Activity by Low-dose Bortezomib Attenuates Angiotensin II-induced Abdominal Aortic Aneurysm in Apo E (-/-) Mice. Sci Rep 2015;5:15730.

15. Tian Z, Zheng H, Li J, Li Y, Su H, Wang X. Genetically induced moderate inhibition of the proteasome in cardiomyocytes exacerbates myocardial ischemia-reperfusion injury in mice. Circ Res 2012;1115:532-42.

16. Aki M, Shimbara N, Takashina M, Akiyama K, Kagawa S, Tamura $\mathrm{T}$, et al. Interferon-gamma induces different subunit organizations and functional diversity of proteasomes. J Biochem 1994;1152:257-69.

17. Goova MT, Li J, Kislinger T, Qu W, Lu Y, Bucciarelli LG, et al. Blockade of receptor for advanced glycation end-products restores effective wound healing in diabetic mice. Am J Pathol 2001;1592:513-25.

18. Brisslert M, Amu S, Pullerits R. Intra-peritoneal sRAGE treatment induces alterations in cellular distribution of CD19(+), CD3 (+) and Mac-1 (+) cells in lymphoid organs and peritoneal cavity. Cell Tissue Res 2013;3511:139-48.

19. Pullerits R, Brisslert M, Jonsson IM, Tarkowski A. Soluble receptor for advanced glycation end products triggers a proinflammatory cytokine cascade via beta2 integrin Mac-1. Arthritis Rheum 2006;5412:3898-907.

20. Gao E, Koch WJ. A novel and efficient model of coronary artery ligation in the mouse. Methods Mol Biol 2013;1037:299-311.

21. Li HH, Kedar V, Zhang C, McDonough H, Arya R, Wang DZ, et al. Atrogin-1/muscle atrophy F-box inhibits calcineurindependent cardiac hypertrophy by participating in an SCF ubiquitin ligase complex. J Clin Invest 2004;1148:1058-71.

22. Li HH, Willis MS, Lockyer P, Miller N, McDonough H, Glass DJ, et al. Atrogin-1 inhibits Akt-dependent cardiac hypertrophy in mice via ubiquitin-dependent coactivation of Forkhead proteins. $\mathbf{J}$ Clin Invest 2007;11711:3211-23.

23. Toldo S, Seropian IM, Mezzaroma E, Van Tassell BW, Salloum FN, Lewis EC, et al. Alpha-1 antitrypsin inhibits caspase-1 and protects from acute myocardial ischemia-reperfusion injury. $\mathrm{J}$ Mol Cell Cardiol 2011;512:244-51.

24. Gao E, Lei YH, Shang X, Huang ZM, Zuo L, Boucher M, et al. A novel and efficient model of coronary artery ligation and myocardial infarction in the mouse. Circ Res 2010;10712: 1445-53.

25. Dang MQ, Zhao XC, Lai S, Wang X, Wang L, Zhang YL, et al. Gene expression profile in the early stage of angiotensin IIinduced cardiac remodeling: a time series microarray study in a mouse model. Cell Physiol Biochem 2015;352:467-76.

26. Oerlemans R, Franke NE, Assaraf YG, Cloos J, van Zantwijk I, Berkers CR, et al. Molecular basis of bortezomib resistance: proteasome subunit beta5 (PSMB5) gene mutation and overexpression of PSMB5 protein. Blood 2008;1126: 2489-99.

27. Pestka S, Krause CD, Walter MR. Interferons, interferon-like cytokines, and their receptors. Immunol Rev 2004;202:8-32.

28. Ganz T. Macrophage function. New Horiz 1993;11:23-7.
29. Frangogiannis NG, Smith CW, Entman ML. The inflammatory response in myocardial infarction. Cardiovasc Res 2002;531: $31-47$.

30. Frangogiannis NG. The mechanistic basis of infarct healing. Antioxid Redox Signal 2006;811-12:1907-39.

31. van Amerongen MJ, Harmsen MC, van Rooijen N, Petersen AH, van Luyn MJ. Macrophage depletion impairs wound healing and increases left ventricular remodeling after myocardial injury in mice. Am J Pathol 2007;1703:818-29.

32. Ranganathan PV, Jayakumar C, Ramesh G. Netrin-1-treated macrophages protect the kidney against ischemia-reperfusion injury and suppress inflammation by inducing $\mathrm{M} 2$ polarization. Am J Physiol Renal Physiol 2013;3047:F948-57.

33. Mao X, Xing H, Mao A, Jiang H, Cheng L, Liu Y, et al. Netrin-1 attenuates cardiac ischemia reperfusion injury and generates alternatively activated macrophages. Inflammation 2014;372: 573-80.

34. Wang Y, Wang H, Piper MG, McMaken S, Mo X, Opalek J, et al. sRAGE induces human monocyte survival and differentiation. J Immunol 2010;1853:1822-35.

35. Huber EM, Basler M, Schwab R, Heinemeyer W, Kirk CJ, Groettrup M, et al. Immuno- and constitutive proteasome crystal structures reveal differences in substrate and inhibitor specificity. Cell 2012;1484:727-38.

36. McCarthy MK, Malitz DH, Molloy CT, Procario MC, Greiner $\mathrm{KE}$, Zhang $\mathrm{L}$, et al. Interferon-dependent immunoproteasome activity during mouse adenovirus type 1 infection. Virology 2016;498:57-68.

37. Bulteau AL, Lundberg KC, Humphries KM, Sadek HA, Szweda PA, Friguet B, et al. Oxidative modification and inactivation of the proteasome during coronary occlusion/reperfusion. J Biol Chem 2001;27632:30057-63.

38. Gurusamy N, Goswami S, Malik G, Das DK. Oxidative injury induces selective rather than global inhibition of proteasomal activity. J Mol Cell Cardiol 2008;442:419-28.

39. Li J, Horak KM, Su H, Sanbe A, Robbins J, Wang X. Enhancement of proteasomal function protects against cardiac proteinopathy and ischemia/reperfusion injury in mice. J Clin Invest 2011;1219:3689-700.

40. Portbury AL, Ronnebaum SM, Zungu M, Patterson C, Willis MS. Back to your heart: ubiquitin proteasome system-regulated signal transduction. J Mol Cell Cardiol 2012;523:526-37.

41. Milano G, Morel S, Bonny C, Samaja M, von Segesser LK, Nicod $\mathrm{P}$, et al. A peptide inhibitor of c-Jun NH2-terminal kinase reduces myocardial ischemia-reperfusion injury and infarct size in vivo. Am J Physiol Heart Circ Physiol 2007;2924:H1828-35.

42. Cai ZP, Shen Z, Van Kaer L, Becker LC. Ischemic preconditioning-induced cardioprotection is lost in mice with immunoproteasome subunit low molecular mass polypeptide-2 deficiency. FASEB J 2008;2212:4248-57.

43. Opitz E, Koch A, Klingel K, Schmidt F, Prokop S, Rahnefeld A, et al. Impairment of immunoproteasome function by beta5i/ LMP7 subunit deficiency results in severe enterovirus myocarditis. PLoS Pathog 2011;79:e1002233. 